\title{
Performance Analysis of WAVE Control Channels for Public Safety Services in VANETs
}

\author{
Jae-Min Lee, Min-Soo Woo, and Sung-Gi Min
}

\begin{abstract}
Vehicular Ad hoc network (VANET) is researched for public safety of vehicles. Safety applications exchange the safety messages among I2V (Infrastructure to Vehicle) and V2V (Vehicle to Vehicle) in VANETs. As several safety applications are running and generating periodic messages on a vehicle, they consume a sizable resources on communication channel. Several organizations identify the high-priority safety applications and recommend safety message generating patterns. These safety messages are carried by WAVE (Wireless Access in Vehicular Environment) and 802.11p standards. We analyze the theoretical maximum vehicle number when the high-priority safety applications are running on vehicles on highly congested communication channel condition. The analysis shows that a few dozen of vehicles can communicate with each other even without any collision on the communication channel. It means that the transmission mechanism of safety messages must be improved to reduce the generated date rate and EDCA mechanism should be improved without changing 802.11p standard. We propose two simple mechanisms. One is used to reduce the transmission data rate and the other for EDCA improvement. Even with these improvements, one hundred vehicles can be accommodated on the $10 \mathrm{MHz}$ control channel allocated by US FCC.
\end{abstract}

Index Terms -DSRC, safety application, VANET, WAVE

\section{INTRODUCTION}

VANETs become an interesting research area after wireless communication technologies have been rapidly developed since US FCC (United States Federal Communication Commission) allocated $75 \mathrm{MHz}$ bandwidth for DSRC (Dedicated Short-Range Communication) in $5.9 \mathrm{GHz}$ frequency area [1]. IEEE releases WAVE (Wireless Access in Vehicular Environment) standards [2] and the 802.11p standard [3] for the service and application running on DSRC.

In WAVE, MAC (Medium Access Control) is different with the original 802.11 MAC in having MAC extension for multichannel of $\mathrm{CCH}$ (Control Channel) and SCH (Service Channel). $802.11 \mathrm{p}$ standard defines the methods of data exchange without the need to establish a BSS (Basic Service Set) and to wait for the association so that vehicles and infrastructures can communicate each other in short time.

NHTSA (National Highway Traffic Safety Administration), USDOT (US Department of Transportation) and CAMP (Crash Avoidance Metrics Partnership) VSCC (Vehicle Safety Communication Consortium) selected 8 high priority applications among many of safety applications [4].

Manuscript received February 17, 2013; revised May 6, 2013.

Authors are with the Department of Computer and Radio Communication Engineering, Korea University, Seoul, Korea (e-mail: jaemin77@korea.ac.kr, geniiwoo@gmail.com,sgmin@korea.ac.kr).
Transmitted data of high-priority safety applications are described in Table I. SAE (Society of Automotive Engineers) defined the message set exchanged in DSRC range as a standard named SAE J2735 [5]. Safety application composes the data frame and data element of DSRC message set then sends them to $\mathrm{I} 2 \mathrm{~V}$ and $\mathrm{V} 2 \mathrm{~V}$ directions.

Safety applications mainly use $\mathrm{CCH}$ following the priority based EDCA (Enhanced Distributed Channel Access) mechanism described in IEEE 802.11 standard. The default parameter set for each AC (Access Category) in $\mathrm{CCH}$ is guided in IEEE 802.11p. FCC sets a policy of the safety message based on the priority. Proposed Message Priorities are described in DSRC Implementation Guide [6].

\begin{tabular}{|c|c|c|c|c|}
\hline Application & $\begin{array}{l}\text { Comm. } \\
\text { Type }\end{array}$ & Freq. & Data transmitted & Range \\
\hline $\begin{array}{l}\text { Traffic } \\
\text { signal } \\
\text { violation } \\
\text { (TSV) } \\
\end{array}$ & $\begin{array}{l}\mathrm{I} 2 \mathrm{~V} \\
\text { one-way, } \\
\mathrm{P} 2 \mathrm{M}\end{array}$ & $10 \mathrm{~Hz}$ & $\begin{array}{l}\text { single status, timing, } \\
\text { surface, heading, light } \\
\text { position, weather }\end{array}$ & $250 \mathrm{~m}$ \\
\hline $\begin{array}{l}\text { Curve speed } \\
\text { warning } \\
(\mathrm{CSW})\end{array}$ & $\begin{array}{l}\mathrm{I} 2 \mathrm{~V} \\
\text { one-way, } \\
\mathrm{P} 2 \mathrm{M}\end{array}$ & $1 \mathrm{~Hz}$ & $\begin{array}{l}\text { curve location, } \\
\text { curvature, speed limit, } \\
\text { bank, surface }\end{array}$ & $200 \mathrm{~m}$ \\
\hline $\begin{array}{l}\text { Emergency } \\
\text { brake lights } \\
(\mathrm{EBL})\end{array}$ & $\begin{array}{l}\text { V2V, } \\
\text { two-way, } \\
\text { P2M }\end{array}$ & $10 \mathrm{~Hz}$ & $\begin{array}{l}\text { position, deceleration, } \\
\text { heading, velocity }\end{array}$ & $200 \mathrm{~m}$ \\
\hline $\begin{array}{l}\text { Pre-crash } \\
\text { sensing } \\
(\mathrm{PCS})\end{array}$ & $\begin{array}{l}\text { V2V, } \\
\text { two-way, } \\
\text { P2M }\end{array}$ & $50 \mathrm{~Hz}$ & $\begin{array}{l}\text { vehicle type, yaw rate, } \\
\text { position, heading, accel. }\end{array}$ & $50 \mathrm{~m}$ \\
\hline $\begin{array}{l}\text { Collision } \\
\text { warning } \\
(\mathrm{CW})\end{array}$ & $\begin{array}{l}\text { V2V, } \\
\text { two-way, } \\
\text { P2M }\end{array}$ & $10 \mathrm{~Hz}$ & $\begin{array}{l}\text { vehicle type, position, } \\
\text { heading, } \\
\text { acceleration, yaw rate }\end{array}$ & $150 \mathrm{~m}$ \\
\hline $\begin{array}{l}\text { Left turn } \\
\text { assist } \\
\text { (LTA) }\end{array}$ & $\begin{array}{l}\mathrm{I} 2 \mathrm{~V} \text { and } \\
\mathrm{V} 2 \mathrm{~V}, \\
\text { one-way, } \\
\mathrm{P} 2 \mathrm{M}\end{array}$ & $10 \mathrm{~Hz}$ & $\begin{array}{l}\text { signal status, timing, } \\
\text { position, direction, road } \\
\text { geom., } \\
\text { heading }\end{array}$ & $300 \mathrm{~m}$ \\
\hline $\begin{array}{l}\text { Lane change } \\
\text { warning } \\
(\mathrm{LCW})\end{array}$ & $\begin{array}{l}\text { V2V, } \\
\text { one-way, } \\
\text { P2M }\end{array}$ & $10 \mathrm{~Hz}$ & $\begin{array}{l}\text { position, heading, } \\
\text { velocity, acceleration, } \\
\text { turn signal status }\end{array}$ & $150 \mathrm{~m}$ \\
\hline $\begin{array}{l}\text { Stop sign } \\
\text { assist } \\
\text { (SSA) }\end{array}$ & $\begin{array}{l}\mathrm{I} 2 \mathrm{~V} \text { and } \\
\mathrm{V} 2 \mathrm{~V}, \\
\text { one-way, } \\
\mathrm{P} 2 \mathrm{M}\end{array}$ & $10 \mathrm{~Hz}$ & $\begin{array}{l}\text { position, velocity, } \\
\text { heading, warning }\end{array}$ & $300 \mathrm{~m}$ \\
\hline
\end{tabular}

\section{WAVE PROTOCOL SACKS}

DSRC uses the layered protocol architecture based on the IEEE 802.11p and IEEE 1609 family standards. DSRC protocol above layer 2 divides into two stacks. General application and service can use both traditional protocols (UDP, TCP and IPv6) and new protocol (WAVE Short Message Protocol). Otherwise, safety applications in vehicular device should use WSMP defined by IEEE 1609.3 
to support safety message efficiently. WSMP is simple, efficient and specifically customized in the vehicular environment instead of layer 3 and 4 Internet protocols. The logical link control (LLC) sub-layer protocol stack uses IEEE 802.2 standard. LLC protocol frequently uses Subnetwork Access Protocol (SNAP) to identify the protocol associated with the payload of upper layer. DSRC MAC and PHY are defined in IEEE 802.11p. Especially, Multi-Channel Operation protocol is newly added in MAC to support multiple channels. This multi-channel operation concept is defined in IEEE 1609.4 standard. Fig. 1 shows the layered architecture for DSRC.

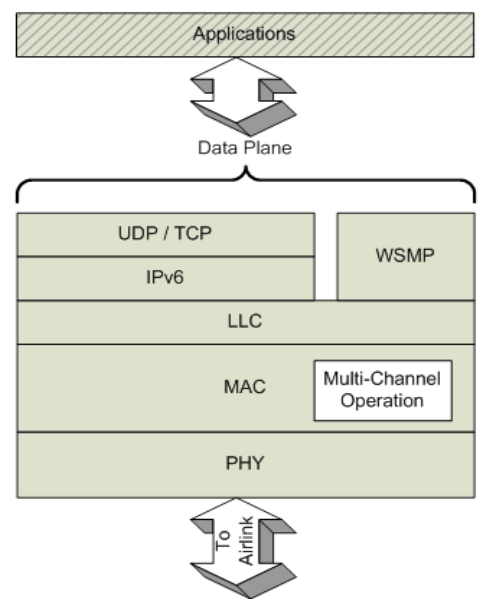

Fig. 1. WAVE protocol stack.

\section{SAFETy MeSSAGE}

TABLE I I: EXAMPLE OF DATA ELEMENT IN SAE J2735 DiCTIONARY

\begin{tabular}{|c|c|}
\hline Name & "DE_Heading \\
\hline Description & $\begin{array}{l}\text { The current heading of the vehicle, expressed in } \\
\text { unsigned units of } 0.010986328 \text { degrees from North } \\
\text { (such that } 32767 \text { such degrees represent } 359.98900 \\
\text { degrees). North shall be defined as the axis defined } \\
\text { by the WSG- } 84 \text { coordinate system and its reference } \\
\text { ellipsoid. Headings "to the east" are defined as the } \\
\text { positive direction. }\end{array}$ \\
\hline Size & 2 byte \\
\hline $\begin{array}{l}\text { ASN.1 } \\
\text { Representation }\end{array}$ & $\begin{array}{l}\text { Heading }::=\text { INTEGER }(0 . .32767) \\
0.010986328 \text { degrees }\end{array}$ \\
\hline $\begin{array}{l}\text { XML } \\
\text { Representation }\end{array}$ & $\begin{array}{l}\text { <xs:simpleType name="Heading" > } \\
\text { <xs:annotation> } \\
\text { <xs:documentation> } \\
\text { LSB of } 0.010986328 \text { degrees } \\
\text { </xs:documentation> } \\
\text { </xs:annotation> } \\
\text { <xs:restriction base="xs:unsignedShort"> } \\
\text { <xs:maxInclusive value="32767"/> } \\
\text { </xs:restriction> } \\
\text { </xs:simpleType> }\end{array}$ \\
\hline Used by & $\begin{array}{ll}\text { DF } & \text { DF_FullPositionVector } \\
\text { DF } & \text { DF_Intersection } \\
\text { DF } & \text { DF_UpdateVector } \\
\text { MSG } & \text { MSG_BasicSafetyMessage_Verbose }\end{array}$ \\
\hline
\end{tabular}

SAE J2735 identifies over 150 Data element for DSRC message in dictionary. Data Elements are the smallest divisions of information content to be standardized. Data Frames are the next level of data structure including the several Data Elements. Combination of Data Frames and Data Elements becomes the Messages. Data Element dictionary in SAE J2735 defines a standard name, description, expressed unit, size, ASN.1 and XML Representations, and other data structure using it. Table II shows an example Data Element.

Data Elements, Data Frames and Messages are described in both Abstract Syntax Notation revision One (ASN.1) and Extensible Markup Language (XML) schema syntax. The ASN.1 is encoded by the Distinguished Encoding Rules (DER). The DER style follows the normal byte-aligned TLV (Type-Length-Value) format of Basic Encoding Rules (BER) for ASN.1 described in Table III.

\begin{tabular}{|c|c|c|c|}
\multicolumn{4}{c}{ TABLE III: ENCODING STRUCTURE OF DER } \\
\begin{tabular}{|c|c|c|c|}
\hline $\begin{array}{c}\text { Identifier } \\
\text { octets } \\
\text { (Type) }\end{array}$ & $\begin{array}{c}\text { Length octets } \\
\text { (Length) }\end{array}$ & $\begin{array}{c}\text { Contents octets } \\
\text { (Value) }\end{array}$ & $\begin{array}{c}\text { End-of-contents } \\
\text { octets }\end{array}$ \\
\hline
\end{tabular}
\end{tabular}

When we look up all Data elements used in the high priority safety applications, 1 byte is enough for Identifier octets because all of them are using universal identifier tags such as INTEGER, ENUMERATED and BIT STRING. In case of Length octet, the value of Data elements are defined in the actual range and it is smaller than 128 bytes. The length octets need just 1byte as short definite form. The byte-aligned primitive value of the Data element follows after length octets. End-of-contents octets can be omitted because we do not use the indefinite length form.

This encoded stream of bytes becomes the payload of lower layer named WAVE Short Message (WSM).

\section{A. Safety Message Size}

As we already described in Table I, the transmitted data of high-priority safety applications are defined based on their characteristics. This data is composed by application which selects the Data Elements, Data Frames and Messages. We can calculate the total size of WSM Data used by application since SAE J2735 pre-defines the data size in its dictionary. C.L. Robinson [7] analyzed the Data Elements usage in the eight NHTSA-defined high priority safety applications. We calculate the total encoded data size of each application and each communication type. Table IV shows the Data Elements, usage and size of data in high-priority safety applications. The encoded WSM data size used in single safety application is 456 to 968 bits depending on the application. It becomes up to 1,408 bits at PHY layer as PSDU after the encapsulation process. This data is sent out periodically based on the application's transmission and receive frequency and latency.

TABLE IV: ANALYSIS OF ELEMENTS USAGE IN HIGH-PRIORITY SAFETY APPLICATION

\begin{tabular}{lcc}
\hline \hline Data Element & $\begin{array}{l}\text { Primitive } \\
\text { data size in } \\
\text { bits }\end{array}$ & $\begin{array}{l}\text { Encoded } \\
\text { data size in } \\
\text { bits }\end{array}$ \\
\hline Acceleration & 12 & 32 \\
Acceleration Precision & 3 & 24 \\
Airbag Count & 7 & 24 \\
Ambient Air Temp. & 8 & 24 \\
Anti-Lock Brake State & 2 & 24 \\
Brake Applied Pressure & 4 & 24 \\
Brake Applied Status & 4 & 24 \\
Brake Boost Applied & 1 & 24 \\
Driving Wheel Angle & 8 & 24 \\
DSRC Message ID & 3 & 24 \\
\hline \hline
\end{tabular}




\begin{tabular}{|c|c|c|}
\hline Elevation Confidence & 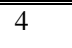 & 24 \\
\hline Elevation & 20 & 40 \\
\hline Exterior Lights & 3 & 24 \\
\hline Heading & 16 & 32 \\
\hline Heading Precision & 3 & 24 \\
\hline Headlights & 2 & 24 \\
\hline Lateral Acceleration & 12 & 32 \\
\hline Latitude of center of vehicle & 32 & 48 \\
\hline Longitude of center of vehicle & 32 & 48 \\
\hline Obstacle Direction & 16 & 32 \\
\hline Obstacle Distance & 10 & 32 \\
\hline Longitudinal Acceleration & 12 & 32 \\
\hline Positioning Precision & 4 & 24 \\
\hline Rain Sensor & 3 & 24 \\
\hline Siren In Use & 2 & 24 \\
\hline Speed & 16 & 32 \\
\hline Speed Precision & 3 & 24 \\
\hline Stability Control Status & 3 & 24 \\
\hline Steering Wheel Angle & 16 & 32 \\
\hline Steering Wheel Angle Precision & 2 & 24 \\
\hline Steering Wheel Rate of Change & 8 & 24 \\
\hline Sun Sensor & 10 & 32 \\
\hline System Health & 4 & 24 \\
\hline Throttle Position & 8 & 24 \\
\hline Throttle Precision & 3 & 24 \\
\hline Time Precision & 4 & 24 \\
\hline Temporary ID & 48 & 64 \\
\hline Traction Control State & 2 & 24 \\
\hline Turn Signal/Hazard Signal & 2 & 24 \\
\hline Two Byte Tag List & 16 & 32 \\
\hline UTC Time & 40 & 56 \\
\hline Vehicle Length & 14 & 32 \\
\hline Vehicle Width & 10 & 32 \\
\hline Vehicle Height & 8 & 24 \\
\hline Vehicle Mass & 8 & 24 \\
\hline Vehicle Type & 7 & 24 \\
\hline Vertical Acceleration & 8 & 24 \\
\hline Vertical Acceleration Threshold & 4 & 24 \\
\hline Wiper Rate & 8 & 24 \\
\hline Wiper Status & 3 & 24 \\
\hline Yaw Rate & 16 & 32 \\
\hline Yaw Rate Precision & 3 & 32 \\
\hline Total Size in Bits & 497 & 1496 \\
\hline
\end{tabular}

\section{B. Safety Message Encapsulation}

DSRC device in VANETs should encapsulate the safety message from application layer to PHY layer. Each layer of WAVE protocol architecture attaches the protocol header in order to compliance with the current layer protocol.

Application selects the message set, data frames and data elements for its purpose from SAE J2735 DSRC message dictionary. Safety application's required data are described in Table I. Those messages are composed and encoded as WAVE Short Message (WSM) format and become the WSMP payload.

Packet using WSMP has the minimum 8 bytes size header including 1 byte WSMP version, 4 bytes Provider service identifier (PSID), 1 byte WSM element ID, and 2 bytes WSM length. If the application wants to put 3 bytes channel number, 3 bytes data rate and 3 bytes transmit power used, the extension fields are added in WSMP header. In this paper, we count 17 bytes WSMP header because the safety applications are using $\mathrm{CCH}$ and the $\mathrm{CCH}$ carries data packets in WSMP format.

WSMP data packets should be encapsulated in LLC along with SNAP header. LLC header includes 1 byte Destination Service Access Point (DSAP) address, 1 byte Source Service Access Point (SSAP) address and 1 byte control field. In case of SNAP, it requires 5 bytes header. The first 3 bytes are the identifier of private or public registry and the last 2 bytes are the indicator of Ether Type such as IPv6 and WSMP. LLC layer delivers the encapsulated packets to WAVE MAC layer as MAC service data unit (MSDU) after adding 17 bytes WSMP header, 5 bytes SNAP header and 3 bytes LLC header upon the original application's WSM Data.

DSRC MAC frame consists of a MAC header, MSDU and Frame check sequence (FCS). Most common MAC header includes 2 bytes Frame control, 2 bytes Duration, 2 bytes Sequence control, 2 bytes QoS (Quality of Service) control, and 18 bytes for 3 addresses of Transmitting station address, Receiving station address and Source address. MAC layer sends the encapsulated packet with 26 bytes MAC header and 4 bytes FCS to DSRC PHY layer as a Physical layer service data unit (PSDU).

DSRC PHY creates a physical layer protocol data unit (PPDU) to transmit it to air link. PPDU consists of 12 bytes physical layer convergence procedure (PLCP) preamble, 5 bytes PLCP header including SIGNAL symbol and Service field, PSDU, 6 bits TAIL and various bits PAD. The data rate of PPDU is encoded in SIGNAL field which is always sent at the lowest data rate (3Mbps in a $10 \mathrm{MHz}$ channel). It means that PLCP preamble and SIGNAL consumes always same time of $40 \mu$ s regardless of the data rate in SIGNAL field. Otherwise, the rest of PPDU after SIGNAL is encoded at indicated data rate in SIGNAL field.

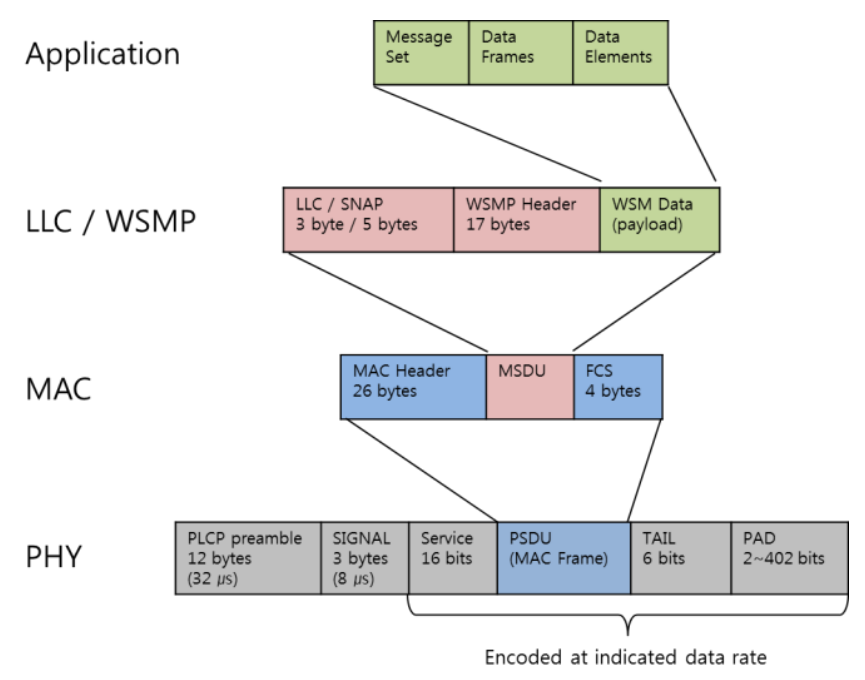

Fig. 2. Message encapsulation process

Once the data rate is fixed by SIGNAL field, PAD varies from 2 to 402 bits because the length of the entire PPDU must be an integer multiple of bits per OFDM (Orthogonal Frequency Division Multiplexing). Fig. 2 shows the message 
encapsulation process. Table V shows the data rate and PLCP overhead in a DSRC $10 \mathrm{MHz}$ channel.

TABLE V: DATA RATE AND PLCP OVERHEAD IN A 10 MHZ DSRC

\begin{tabular}{|c|c|c|c|c|c|}
\hline \multicolumn{6}{|c|}{ CHANNEL } \\
\hline $\begin{array}{l}\text { Data } \\
\text { rate } \\
(\mathrm{Mbps})\end{array}$ & $\begin{array}{l}\text { Data } \\
\text { bits per } \\
\text { OFDM } \\
\text { symbol }\end{array}$ & $\begin{array}{l}\text { Preamble } \\
(\mu \mathrm{s})\end{array}$ & $\begin{array}{l}\text { SIGNAL } \\
(\mu \mathrm{s})\end{array}$ & $\begin{array}{l}\text { Service, } \\
\text { TAIL, the } \\
\text { longest } \\
\text { PAD }(\mu s)\end{array}$ & $\begin{array}{l}\text { Total } \\
\text { PLCP } \\
\text { overhead } \\
(\mu s)\end{array}$ \\
\hline 3 & 24 & 32 & 8 & 13.3 & 53.3 \\
\hline 6 & 48 & 32 & 8 & 14.6 & 54.6 \\
\hline 12 & 96 & 32 & 8 & 15.3 & 55.3 \\
\hline 27 & 216 & 32 & 8 & 15.7 & 55.7 \\
\hline
\end{tabular}

\section{The CANnEl Allocation Time AND THE UPPER Limits} OF VEHICLES IN VANETS

\section{A. EDCA Mechanism and Parameters on the $\mathrm{CCH}$}

DSRC MAC follows the priority based EDCA (Enhanced Distributed Channel Access) mechanism described in IEEE 802.11 standard. EDCA waits for Arbitrary Inter Frame Space (AIFS):

\section{AIFS $[\mathrm{AC}]=\mathrm{SIFS}+\mathrm{AIFS} \times \mathrm{aSlot}$ Time}

where SIFS is Short Inter Frame Space, AIFSN[AC] is AIFS Number based on Access Category).

If the medium is idle after AIFS [AC], the application can take the transmission opportunity (TXOP). Application having TXOP transmits the packet during the Packet transmission time $T_{t x}$ :

$$
T_{t x}=\text { PSDU size } / \text { Data rate }
$$

where PSDU is Physical layer service data unit (MAC frame size) in bits, Data rate is the transmission data rate.

If the medium is busy after AIFS[AC], the application does back-off to take the TXOP according to the contention window minimum size $\left(\mathrm{CW}_{\min }\right)$ :

$$
\text { Backoff Interval }=\left[0 \cdots \mathrm{CW}_{\min }[\mathrm{AC}]\right] \times \text { aSlotTime }
$$

where $\left[0 \cdots \mathrm{CW}_{\min }[\mathrm{AC}]\right]$ is a random number between 0 and $\mathrm{CW}_{\text {min }}[\mathrm{AC}]$.

Table VI shows the default parameter set for each AC (Access Category) of CCH guided in IEEE 802.11p.

TABLE VI: CONTENTION WINDOW SIZE AND AIFSN BASED ON AC

\begin{tabular}{lllll}
\hline \hline $\mathrm{ACI}$ & $\mathrm{AC}$ & $\mathrm{CW}_{\min }$ & $\mathrm{CW}_{\max }$ & $\mathrm{AIFSN}$ \\
\hline 1 & $\begin{array}{l}\text { Back- } \\
\text { ground }\end{array}$ & $\mathrm{aCW}_{\min }$ & $\mathrm{aCW}_{\max }$ & 9 \\
\hline 0 & $\begin{array}{l}\text { Best } \\
\text { effort }\end{array}$ & $\left(\mathrm{aCW}_{\min }+1\right) / 2-1$ & $\mathrm{aCW}_{\min }$ & 6 \\
\hline 2 & Video & $\left(\mathrm{aCW}_{\min }+1\right) / 4-1$ & $\left(\mathrm{aCW}_{\min }+1\right) / 2-1$ & 3 \\
\hline 3 & Voice & $\left(\mathrm{aCW} \mathrm{CW}_{\min }+1\right) / 4-1$ & $\left(\mathrm{aCW}_{\min }+1\right) / 2-1$ & 2 \\
\hline \hline
\end{tabular}

Other parameter values are listed in Table VII.

Proposed Message Priorities are described in DSRC Implementation Guide - A guide to users of SAE J2735 message sets over DSRC. Message Priority is set by Importance Level from FCC Policy. In case of level 1(Safety of Life), those messages and message sets requiring immediate or urgent transmission are using ACI 3 and $\mathrm{CCH}$. The message sets used in 8 high-priority applications are also using ACI 3. Consequently, AIFSN[AC] for AIFS is 2 and $\mathrm{CW}_{\min }[\mathrm{AC}]$ for back off interval is a random number between 0 and 3 .

TABLE VII: EDCA PARAMETER SET USED ON THE CCH

\begin{tabular}{ll}
\hline \hline Parameter & Value \\
\hline $802.11 \mathrm{p}$ (802.11a modification) slot time & $13 \mu \mathrm{s}$ \\
$\mathrm{SIFS}$ & $32 \mu \mathrm{s}$ \\
$\mathrm{aCW}_{\min }$ & 15 \\
$\mathrm{aCW}_{\max }$ & 1023 \\
\hline \hline
\end{tabular}

\section{B. I2Vand V2V Classification}

$\mathrm{CCH}$ interval is set to $1000 \mathrm{~ms}$ ( 1 second). Both $\mathrm{I} 2 \mathrm{~V}$ and $\mathrm{V} 2 \mathrm{~V}$ communication type share the same medium. I2V means that from Infrastructure to Vehicles so it generally uses one way broadcasting way. Otherwise, V2V is the two way communication required contention based channel access. Among 8 high-priority safety applications, Traffic signal violation, Curve speed warning, Left turn assist and Stop sign assist use I2V communication. If we assume that the applications run on the lowest data rate $3 \mathrm{Mbps}$, we can calculate overall time for $\mathrm{I} 2 \mathrm{~V}$ communication.

Message size can be obtained from Table IV. In order to calculate the $T_{t x}$ by equation (2), PSDU size is increased because of PSDU encapsulation (25 bytes for LLC/WSMP and 30 bytes for MAC layer same as 440 bits). If PHY layer also same data rate, the time for PHY layer $T_{\text {phy }}$ is

$$
T_{\text {phy }}=T_{\text {preamble }}+T_{\text {signal }}+T_{\text {pad }}
$$

where $T_{\text {preamble }}$ is time for TLCP preamble, $T_{\text {signal }}$ is time for SIGNAL, and $T_{\mathrm{pad}}$ is time for Service/TAIL/PAD. Total PLCP overhead (the time for PHY layer Tphy) is in Table V.

TABLE VIII: APPLICATIONS USING I2V COMMUNICATION.

\begin{tabular}{l|l|l|l|l|l}
\hline & PSDU & $\begin{array}{l}\text { Total } \\
\text { time } \\
\text { with 3 } \\
\text { Application in } \\
\text { bits } \\
\text { Mbps } \mu \mathrm{s}\end{array}$ & $\begin{array}{l}\text { Total } \\
\text { time } \\
\text { with 6 } \\
\text { Mbps } \\
\text { in } \mu \mathrm{s}\end{array}$ & $\begin{array}{l}\text { Total } \\
\text { time } \\
\text { with 12 } \\
\text { Mbps } \\
\text { in } \mu \mathrm{s}\end{array}$ & $\begin{array}{l}\text { Total } \\
\text { time } \\
\text { with 27 } \\
\text { Mbps } \\
\text { in } \mu \mathrm{s}\end{array}$ \\
\hline $\begin{array}{l}\text { Traffic signal } \\
\text { violation }\end{array}$ & 1120 & 373.6 & 186.7 & 93.3 & 41.5 \\
\hline $\begin{array}{l}\text { Curve speed } \\
\text { warning }\end{array}$ & 1376 & 458.7 & 229.3 & 114.7 & 51 \\
\hline $\begin{array}{l}\text { Left turn } \\
\text { signal }\end{array}$ & 1136 & 378.7 & 189.3 & 94.7 & 42.1 \\
\hline $\begin{array}{l}\text { Stop sign } \\
\text { assist }\end{array}$ & 1016 & 338.7 & 169.3 & 84.7 & 37.6 \\
\hline $\begin{array}{l}\text { Total time for I2V } \\
\text { communication in ms }\end{array}$ & 13 & 7.4 & 4.6 & 3.0 \\
\hline \hline
\end{tabular}

Table VIII shows the applications using I2V communication and their data size and channel occupation time for one packet transmission. Curve speed warning application sends a message packet just one time because it has $1 \mathrm{~Hz}$ frequency in $1000 \mathrm{~ms}$. Otherwise, Traffic signal violation, Left turn assist and Stop sign assist applications send a packet 10 times in every $100 \mathrm{~ms}$ because those applications have $10 \mathrm{~Hz}$ frequency and $100 \mathrm{~ms}$ latency. When 
we count all packet transmission time according to the applications' frequency and latency, I2V applications using 3 Mbps data rate consume $13 \mathrm{~ms}$ of $1000 \mathrm{~ms}$ in total $\mathrm{CCH}$ interval. The rest of $\mathrm{I} 2 \mathrm{~V}$ one way broadcasting in $\mathrm{CCH}$ is dedicated for $\mathrm{V} 2 \mathrm{~V}$ communication which is contention based channel access.

\section{V2V Communication in $\mathrm{CCH}$}

There are 6 applications using V2V communication among 8 high-priority safety applications. The message size and transmission time for one packet in $3 \sim 27 \mathrm{Mbps}$ data rate are list up in Table IX below. In case of V2V communication, we should consider medium status which is either idle or busy. We assume that the medium is always busy because of the upper limits in the worst case. Each application being faced with busy medium needs AIFS [AC] and random back-off before getting TXOP. Consequently, V2V application consumes AIFS [AC], random back-off, $T_{\text {phy }}$ and $T_{\mathrm{tx}}$ for one packet transmission.

TABLE IX: APPLICATIONS USING V2V COMMUNICATION

\begin{tabular}{llllll}
\hline \hline Application & $\begin{array}{l}\text { PSDU } \\
\text { in bits }\end{array}$ & $\begin{array}{l}T_{t \mathrm{x}} \\
(3 \mathrm{Mbps}) \\
\text { in } \mu \mathrm{s}\end{array}$ & $\begin{array}{l}T_{\mathrm{tx}} \\
(6 \mathrm{Mbps})\end{array}$ & $\begin{array}{l}T_{\mathrm{tx}} \\
(12 \mathrm{Mbps})\end{array}$ & $\begin{array}{l}T_{\mathrm{tx}} \\
(27 \mathrm{Mbps})\end{array}$ \\
\hline $\begin{array}{l}\text { in } \mu \mathrm{s} \\
\text { inergency } \\
\text { brake lights }\end{array}$ & 896 & 298.7 & 149.3 & 74.7 & 33.2 \\
\hline $\begin{array}{l}\text { Pre-crash } \\
\text { sensing }\end{array}$ & 1184 & 394.7 & 197.3 & 98.7 & 43.9 \\
\hline $\begin{array}{l}\text { Collision } \\
\text { warning }\end{array}$ & 1408 & 469.3 & 234.7 & 117.3 & 52.1 \\
\hline $\begin{array}{l}\text { Left turn } \\
\text { assist }\end{array}$ & 1136 & 378.7 & 189.3 & 94.7 & 42.1 \\
\hline $\begin{array}{l}\text { Lane } \\
\text { change } \\
\text { warning }\end{array}$ & 1152 & 384 & 192 & 96 & 42.7 \\
\hline $\begin{array}{l}\text { Stop sign } \\
\text { assist }\end{array}$ & 1016 & 338.7 & 169.3 & 84.7 & 37.6 \\
\hline \hline
\end{tabular}

AIFS $[\mathrm{AC}]$ and random back-off interval can be calculated by equation (1) and (3)

AIFS $[$ AC $]=$ SIFS time $(32 \mu \mathrm{s})+$ AIFSN $[$ AC $] \times$ aSlotTime $=32+2 \times 13=58 \mu \mathrm{s}$

Random back-off $=\left[0 \cdots \mathrm{CW}_{\min }[\mathrm{AC}]\right] \times$ aSlotTime $=$ Avg. $2 \times 13=26 \mu \mathrm{s}$

Random back-off number should be chosen between 0 and 3 . Therefore, we assume the average number 2 for the simple calculation. Lastly, V2V application consumes $T_{\mathrm{tx}}$ and $T_{\text {phy }}$ according to the data rate as described in Table IX and Table V. The full picture of channel access time for one safety application in busy medium is described in Fig. 3 .

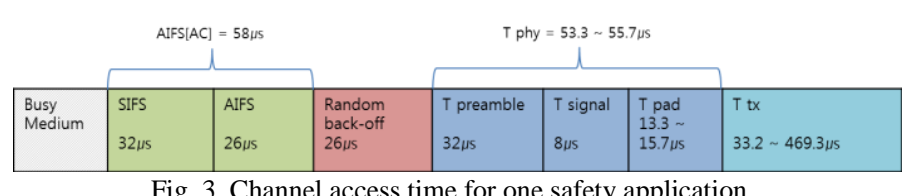

Fig. 3. Channel access time for one safety application

Emergency brake lights, Collision Warning, Left turn assist, Lane change warning and Stop sign assist must transmit the safety message in every $100 \mathrm{~ms}$. Pre-crash sensing must transmit the safety message in every $20 \mathrm{~ms}$. When we set the data rate to the lowest data rate $3 \mathrm{Mbps}$, we describe the total time for $100 \mathrm{~ms}$ latency applications and 20ms latency application in Fig. 4 and 5.

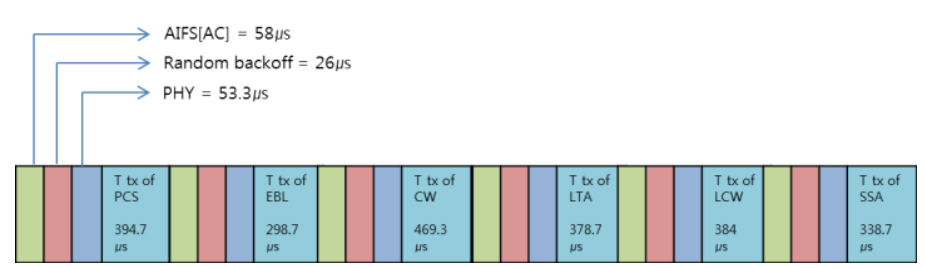

Fig. 4. Messages in every $100 \mathrm{~ms}(50 \mathrm{~Hz} \mathrm{msg}+10 \mathrm{~Hz} \mathrm{msg})$, total $=3.1 \mathrm{~ms}$

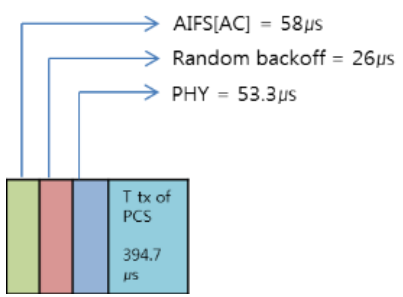

Fig. 5. Messages in every $20 \mathrm{~ms}(50 \mathrm{~Hz} \mathrm{msg})$, total $=532 \mu \mathrm{s}$

\section{The Upper Limits of Vehicles}

As we analyze the each application's medium occupation in both $\mathrm{I} 2 \mathrm{~V}$ and $\mathrm{V} 2 \mathrm{~V}$ communications, we now calculate the upper limit of vehicles which run 8 safety applications at the same time. When we set the data rate to the lowest data rate $3 \mathrm{Mbps}$, I2V one-way broadcasting communication type applications spend $13 \mathrm{~ms}$ of $\mathrm{CCH}$ Interval is $1000 \mathrm{~ms}$. Therefore, V2V communication type applications share $987 \mathrm{~ms}$ of $\mathrm{CCH}$ Interval as contention period. We only stay focus on the contention period for $\mathrm{V} 2 \mathrm{~V}$ communication because the time for I2V isn't changed in spite of the increased vehicles' number.

The applications having $10 \mathrm{~Hz}$ and $50 \mathrm{~Hz}$ frequency should transmit the messages in every $100 \mathrm{~ms}$ latency at the same time. These events happen 10 times during the $\mathrm{CCH}$ interval. The application having $50 \mathrm{~Hz}$ frequency should transmit the message in every $20 \mathrm{~ms}$. It tries to send a message 50 times but 10 times are sent along with $10 \mathrm{~Hz}$ applications as described in Fig. 4.

When the data rate is $3 \mathrm{Mbps}$, the total required time is $52.2 \mathrm{~ms}$ which is the sum of messages in every $100 \mathrm{~ms}$ and messages in $20 \mathrm{~ms}$. How the messages consume the $\mathrm{CCH}$ interval in detail is described in Fig. 6. Since the medium occupation for 1 vehicle with 8 high priority safety applications is fixed, we can conclude the upper limits of safety service vehicle (V limits):

$$
\mathrm{V} \text { limits }=T_{c c h} / T_{\text {apps }}
$$

where $T_{\text {cch }}$ is the contention period in $\mathrm{CCH}$ interval and $T_{\text {apps }}$ is the times for the safety applications.

In case of $3 \mathrm{Mbps}$ data rate, $T_{\text {cch }}$ and $T_{\text {apps }}$ are like below.

$T_{\text {cch }}=\mathrm{CCH}$ Interval $(1000 \mathrm{~ms})-$ Time for I $2 \mathrm{~V}(13 \mathrm{~ms})=987$ $\mathrm{ms}$

$T_{\text {apps }}=$ Messages in every $100 \mathrm{~ms}(3.1 \mathrm{~ms} \times 10$ times $)+$ Messages in every $20 \mathrm{~ms}(532 \mu \mathrm{s} \times 40$ times $)=52.2 \mathrm{~ms}$

If we put the vales of $T_{\text {cch }}$ and $T_{\text {apps }}$ into equation (5), the upper limits of safety service vehicles with 8 high priority applications are V limits $=987 / 52.2=18.90$

It means that 18 vehicles can run safety service without the 
safety message collision probability in $3 \mathrm{Mbps}$ data rate VANETs.
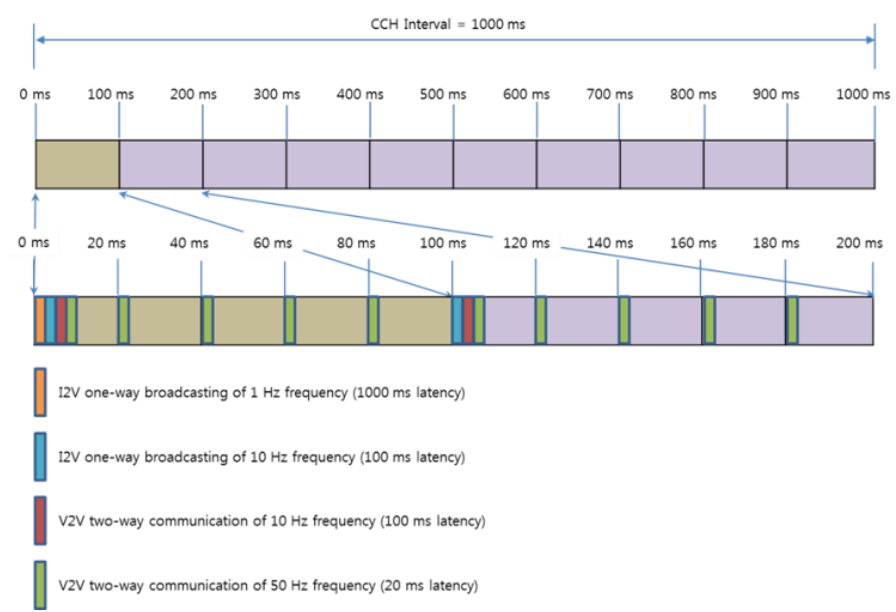

Fig. 6. Medium occupation in $\mathrm{CCH}$

\section{ANALYSIS RESULTS IN VARIOUS ENVIRONMENTS}

We assume the worst cases such as always busy medium and the lowest data rate for analyzing the upper limits because one safety message collision in VANETs may cause the critical damage to vehicles and drivers. When we consider the safety application's range around 200 meters, 18 vehicles in $3 \mathrm{Mbps}$ data rate VANETs are fairly not enough number in congestion road condition. Therefore, we can suggest various approaches and analysis results in order to improve the upper limits.

\section{A. Data Rates}

VANETs standards provide the various data rates up to $27 \mathrm{Mbps}$ in $10 \mathrm{MHz}$ single $\mathrm{CCH}$. Higher data rates can reduce the packet transmission time even in same PSDU size. Even though AIFS and Random back-off interval are not changed by the higher data rate, the reduced packet transmission time becomes the overall gain in the view point of channel usage. The mandatory support data rates are 3, 6, 12 and 27Mbps in $10 \mathrm{MHz}$ single $\mathrm{CCH}$. When we apply the maximum data rate $27 \mathrm{Mbps}$, the upper limits go to 54 vehicles from 18 vehicles in $3 \mathrm{Mbps}$ data rate. Fig. 7 shows the upper limits in various data rates.

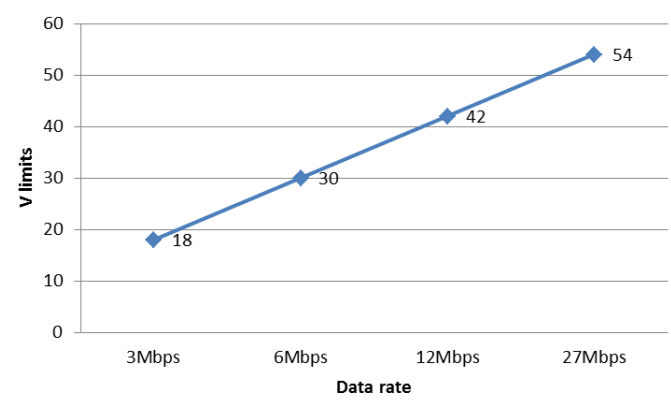

Fig. 7. The V limits in various data rates of single $\mathrm{CCH}$

\section{B. Frame Aggregation}

Frame aggregation has been adopted by the IEEE $802.11 \mathrm{n}$ amendments to reduce timing and header overheads. It assembles several frames into a single large frame for transmission. [8] When we apply this technique, the aggregated frame message of $100 \mathrm{~ms}$ latency safety applications can be described as Fig. 8. Since the frame aggregation uses only a single channel access, we can save the time and improve channel efficiency. It also leads to increase $\mathrm{V}$ limits in $\mathrm{CCH}$ as shown in Fig. 9.

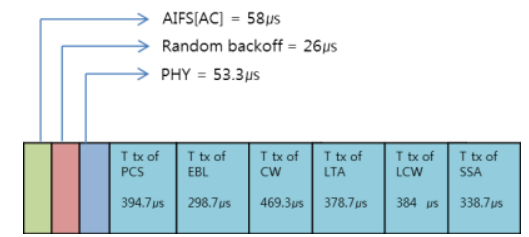

Fig. 8. Aggregated frame Message in every $100 \mathrm{~ms}$, total time $=2.4 \mathrm{~ms}$

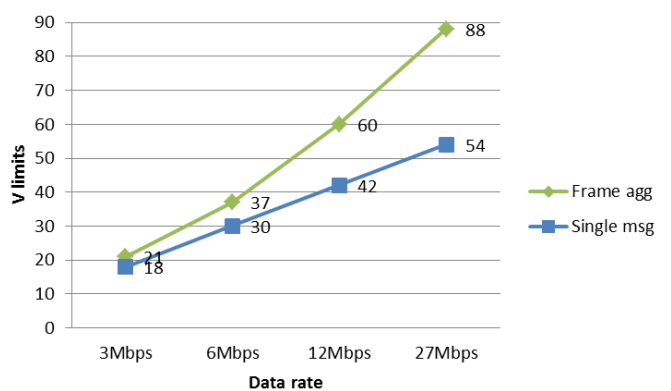

Fig. 9. The V limits of aggregated frame message usage in $\mathrm{CCH}$

\section{Common Message}

We analyze that the biggest overhead of channel occupation is the repeated PHY, AIFS [AC] and random back-off due to separate transmission attempt by each safety application as shown in Fig. 4. If the vehicle has the central unit to control the all safety applications' message transmission, the applications having same message frequency and latency may send the message at once through the central unit. For instance, 6 safety applications are trying to send the messages in $100 \mathrm{~ms}$ latency and those applications require 6 trials of PHY, AIFS [AC], and random back off. Therefore, sending the message at once can reduce this repeated time to $1 / 6$.

We also recognize that many Data elements are commonly used by 8 safety application while analyzing of elements usage in High-priority safety application listed in Table IV. When the central unit assembles the common message, the duplicated data elements are removed by common message.

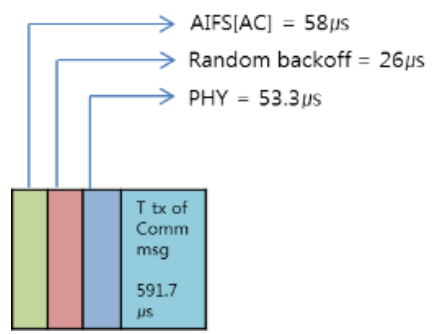

Fig. 10. Common Message in every $100 \mathrm{~ms}$, total time $=729.3 \mu \mathrm{s}$

By transmitting the common message at once with $3 \mathrm{Mbps}$ data rate instead of 6 separate messages, the channel occupation time for $\mathrm{V} 2 \mathrm{~V}$ communication in every $100 \mathrm{~ms}$ is reduced from $3.1 \mathrm{~ms}$ in Fig. 4 to $729.3 \mu \mathrm{s}$ in Fig. 10. I2V communications also use common messages in the same way of $\mathrm{V} 2 \mathrm{~V}$ communication. The channel occupation time for 
$\mathrm{I} 2 \mathrm{~V}$ communication in every $100 \mathrm{~ms}$ is reduced from $13 \mathrm{~ms}$ to $5.3 \mathrm{~ms}$ in $3 \mathrm{Mbps}$ data rate. Those common messages distinctly increases $\mathrm{V}$ limits in $\mathrm{CCH}$ as shown in Fig. 11.

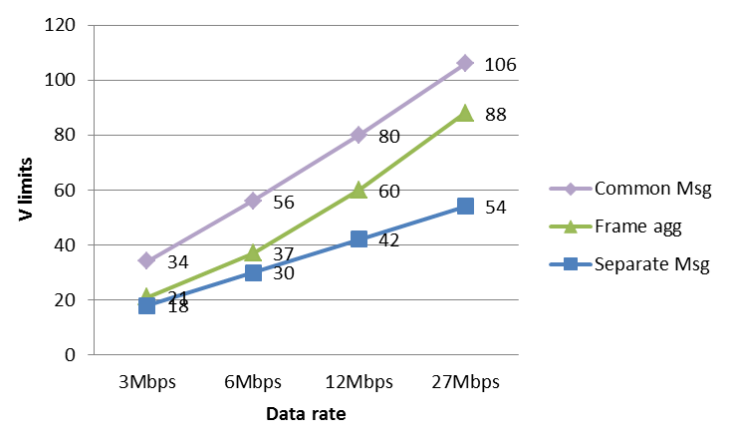

Fig. 11. The $\mathrm{V}$ limits of common message usage in $\mathrm{CCH}$

\section{Compressed Common Message}

The last approach is compressing the message before transmitting it. If the central unit has the message compression functionality, we can reduce the message size. When we apply the median compression rate, the compressed message size can be reduced to $35 \%$ of original message [9]. As the message size is reduced by compression, application can shorten the message transmission time. Fig. 12 and Fig. 13 show the compressed common message of 100ms latency and Pre-crash sensing (PCS) message 20ms latency.

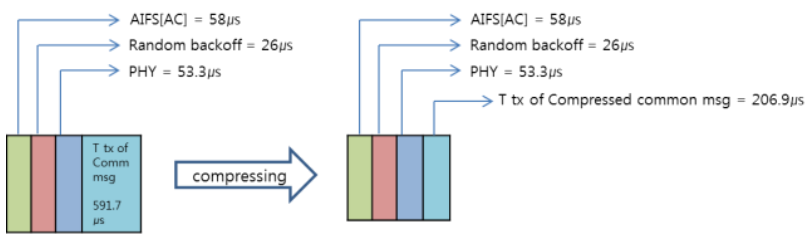

Fig. 12. Compressed common Message in every $100 \mathrm{~ms}$, total time $=344.5 \mu \mathrm{s}$

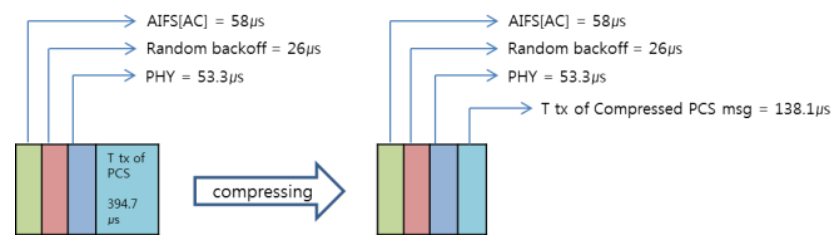

Fig. 13. Compressed PCS Message in every $20 \mathrm{~ms}$, total time $=275.4 \mu \mathrm{s}$

Even though AIFS [AC], back-off time and $T_{\text {phy }}$ are not changed by compression, $T_{t x}$ of compressed message becomes much smaller than $T_{t x}$ of non-compressed message. This compression technique increases $\mathrm{V}$ limits in $\mathrm{CCH}$ as shown in Fig. 14.

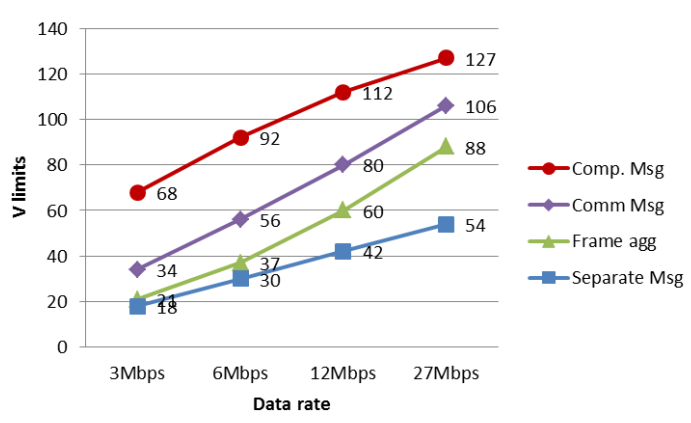

Fig. 14. The V limits of compressed message usage in $\mathrm{CCH}$

\section{CONCLUSION AND FUTURE WORDS}

In this paper, we have analyzed the performance of WAVE Control Channels for public safety services in VANET. We propose the high data rate, the aggregated frame message, the common message and the compressed message. We confirm that proposed approaches improve the $\mathrm{V}$ limits. In spite of the improved vehicle number in VANETs, the number is still insufficient to cover the fluent communication in congestion road. C.L. Robinson [10] insists that the predictive coding can significantly reduce the channel load in vehicular safety application by avoiding the duplicated data and sending the data at minimum required update rate. The common message, the compressed message and the predictive coding need additional non-standard unit. Those non-standard approaches may have compatibility issues in VANET. The performance analysis presented in this paper will assist VANETs designers and future researchers who design their networks and handle the channel capacity by optimizing the data rate, channel and messages.

Future work can be directed towards further investigation of the random backoff counter and contention probability that we use constant number and always busy medium condition.

\section{REFERENCES}

[1] ASTM E2213-03, "Standard specification for telecommunications and information exchange between roadside and vehicle system - $5 \mathrm{GHz}$ band dedicated short range communications (DSRC) medium access control (MAC) and physical layer (PHY) specifications," ASTM, September 2003.

[2] IEEE 1609, "Family of Standards for Wireless Access in Vehicular Environments (WAVE), " IEEE, 2007.

[3] IEEE 802.11p, "Standard for Information Technology Telecommunications and Information Exchange between systems Local and Metropolitan networks - Specific requirements; Part 11: Wireless LAN Medium Access Control (MAC) and Physical Layer (PHY) specifications; Amendment 7: Wireless Access in Vehicular Environments," IEEE, 2010.

[4] CAMP Vehicle Safety Communication Consortium, "Vehicle Safety Communications Project Task 3 Final Report - Identify Intelligent Vehicle Safety Applications Enabled by DSRC," DOT HS 809859 , March 2005

[5] Society of Automotive Engineers, "Dedicated Short Range Communication (DSRC) Message Set Dictionary," SAE J2735, 2009.

[6] Society of Automotive Engineers, "DSRC Implementation Guide - A guide to users of SAE J2735 message sets over DSRC," SAE International, 2010

[7] C. L. Robinson, L. Caminiti, D. Caveney, and K. Laberteaux, "Efficient Coordination and Transmission of Data for Cooperative Vehicular Safety Applications," in Proc. the 3rd international workshop on Vehicular ad hoc networks

[8] A. Saif, M. Othman, S. Subramaniam, and N. A. W. A. Hamid, "Frame Aggregation in Wireless Networks: Techniques and Issues," IETE Technical Review, vol. 28, issue 4, Jul.-Aug., 2011.

[9] Airelle. (2007). Comparative performance different methods of compressing files. [Online]. Available: http://rlwpx.free.fr/WPFF/comploc.htm

[10] C. L Robinson, VANET: Vehicular Applications and Inter-Networking Technologies, John Wiley \& Sons, Ltd, 2010, pp. 287-294

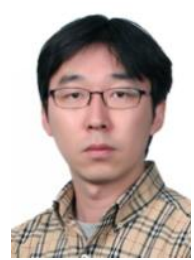

Jae-Min Lee received his B.S. degree in Electronics Convergence Engineering from Kwangwoon University, Seoul, Korea, in 2003. Currently, he is working towards the M.S. degree in Computer Science at Korea University, Seoul, Korea. Since February 2003, he has been a senior engineer of Mobile Communication Division at Samsung Electronics Co., Ltd. His research interests are Software Platform for Mobile device,

Wireless network and Mobile application. 


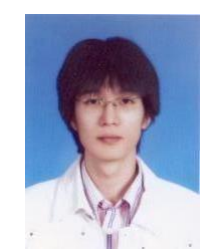

Min-Soo Woo received his B.S. and M.S. degrees in Computer Science from Korea University, Seoul, Korea, in 2007 and 2009. Currently, he is working towards the $\mathrm{Ph} . \mathrm{D}$. degree in Computer Science at Korea University, Seoul, Korea. . His research interests mobility protocols such as MIP, PMIP, VANET, and mobility management in future network.

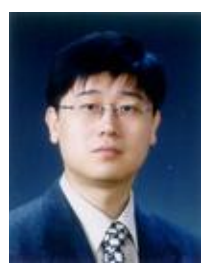

Sung-Gi Min received his B.S. degree in Computer Science from Korea University, Seoul, Korea, in 1988

He received his M.S. and Ph.D. degrees in Computer Science from University of London in 1989 and 1993 respectively. From 1 January 1994 to 28 February 2000, he worked in LG Information and communication Research Center, and from 2 March 2000 to 28 February 2001, he was a Professor in the Department of Computer Engineering at Dongeui University, Busan, Korea. Since 2 March 2001, he has been a Professor in the Department of Computer Science and Engineering at Korea University, Seoul, Korea. His research is focused to wired/wireless communication networks, especially heterogeneous network environment, and he is interested in mobility protocols such as MIP PMIP, network architectures, QoS, VANET, and mobility management in future network. 